\title{
Ischemic mitral valve prolapse
}

\author{
Francesco Nappi ${ }^{1}$, Spadaccio Cristiano ${ }^{2,3}$, Antonio Nenna ${ }^{4}$, Massimo Chello ${ }^{4}$ \\ ${ }^{1}$ Cardiac Surgery Centre Cardiologique du Nord de Saint-Denis, Paris, France; ${ }^{2}$ Department of Cardiothoracic Surgery, Golden Jubilee National \\ Hospital, Glasgow, UK; ${ }^{3}$ University of Glasgow Institute of Cardiovascular and Medical Sciences, Glasgow, UK; ${ }^{4}$ Department of Cardiovascular \\ Surgery, University Campus Bio-Medico di Roma, Rome, Italy \\ Contributions: (I) Conception and design: F Nappi; (II) Administrative support: M Chello; (III) Provision of study materials or patients: F Nappi; (IV) \\ Collection and assembly of data: F Nappi, S Cristiano; (V) Data analysis and interpretation: F Nappi, S Cristiano, A Nenna; (VI) Manuscript writing: \\ All authors; (VII) Final approval of manuscript: All authors. \\ Correspondence to: Francesco Nappi, MD. Cardiac Surgery, Centre Cardiologique du Nord de Saint-Denis, 36 Rue des Moulins Gémeaux, 93200 \\ Saint-Denis, Paris, France. Email: francesconappi2@gmail.com.
}

\begin{abstract}
Ischemic mitral prolapse (IMP) is a pathologic entity encountered in about one-third among the patients undergoing surgery for ischemic mitral regurgitation (IMR). IMP is generally the result of a papillary muscle injury consequent to myocardial, but the recent literature is progressively unveiling a more complex pathogenesis. The mechanisms underlying its development regards the impairment of one or more components of the mitral apparatus, which comprises the annulus, the chordae tendineae, the papillary muscle and the left ventricular wall. IMP is not only a disorder of valvular function, but also entails coexistent aspects of a geometric disturbance of the mitral valve configuration and of the left ventricular function and dimension and a correct understanding of all these aspects is crucial to guide and tailor the correct therapeutic strategy to be adopted. Localization of prolapse, anatomic features of the prolapsed leaflets and the subvalvular apparatus should be carefully evaluated as also constituting the major determinants defining patient's outcomes. This review will summarize our current understanding of the pathophysiology and clinical evidence on IMP with a particular focus on the surgical treatment.
\end{abstract}

Keywords: Mitral valve; prolapse; ischemic mitral regurgitation (IMR); functional mitral regurgitation; surgery

Submitted Oct 17, 2016. Accepted for publication Nov 09, 2016.

doi: $10.21037 /$ jtd.2016.12.33

View this article at: http://dx.doi.org/10.21037/jtd.2016.12.33

\section{State of the art}

Ischemic mitral prolapse (IMP) is a consequence, easily overlooked, of adverse valvular dysfunction secondary to the papillary muscle injury after myocardial infarction (MI) (1-6). IMR affects more than one third of patients with ischemic mitral regurgitation (IMR) with a larger predominance in male approximately $3: 1$ (4). These processes led to a regional ventricular injury or wall motion abnormality rather than a global LV dysfunction $(7,8)$ and the clinical and echocardiographic evidence are more daunting than any other ischemic cardiac lesion $(9,10)$. Indeed, clinical studies have suggested that the knowledge on IMP disease is incomplete and questions remain unanswered about the morphological and functional impairment of annulus and subvalvular apparatus (11-15). Although much of the original focus is centered on the abnormal restriction of leaflet valve, the disease is significantly more complex (16-18). The consequence of IMP is not only related to a disorder of valvular function, but also implicates coexistent futures of a geometric disturbance of the mitral valve configuration and of the left ventricular function and dimension $(13,19,20)$. This review will summarize our current understanding of the pathophysiology, clinical use and clinical evidence of IMP disease with a focus on the surgical treatment.

\section{Pathophysiology}

A normal mitral valve is composed by two mitral valve 
A

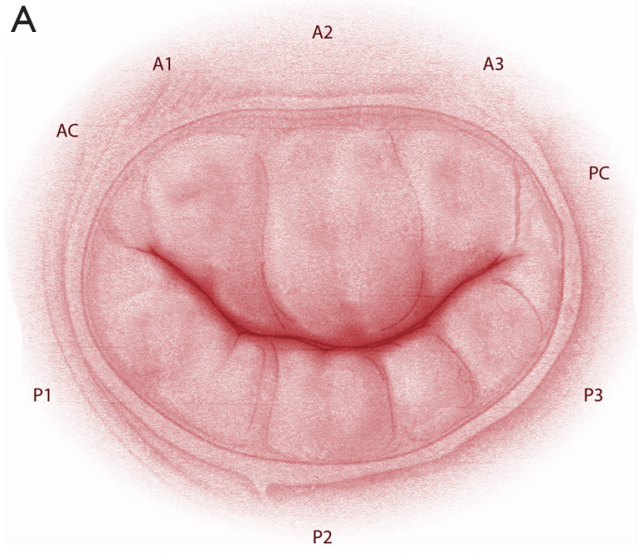

B

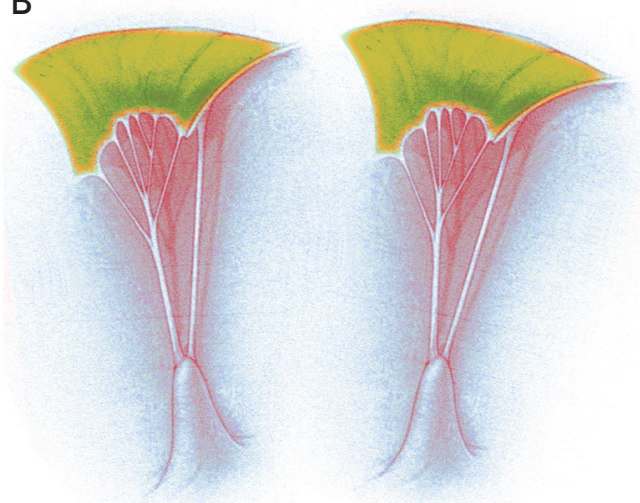

Figure 1 Anatomy of the mitral valve apparatus. (A) Mitral valve and anatomical description of anterior, posterior leaflet and relative scallops; (B) representation of papillary muscle and chordae tendineae with attachment on the mitral leaflets.

leaflets and subvalvular apparatus. The cusps, named anterior and posterior, are attached in the fibrous annulus. The chordae tendineae link the anterior and posterior leaflet to papillary muscles, and left ventricular wall (Figure 1). The papillary muscle is classed in antero lateral and posteromedial papillary muscles and each papillary muscle provides chordae to both leaflets. Valvular leaflet typically consists of three distinct zones or scallops, namely P1, P2, and $\mathrm{P} 3$ in the posterior mitral-valve leaflet, and A1, A2, and $\mathrm{A} 3$ in the anterior leaflet. Competence and proper functioning of the mitral valve relies on the coordinated interaction of the valve and subvalvular apparatus.

\section{Patterns of papillary muscle morphology and lesion}

Some experts in mitral anatomy revealed a range of morphological diversity of PM anatomy and led to an anatomical classification with important implications in IMR surgery (21). Papillary muscle valve typically comprises five segmentation and morphological types $(3,4)$. The most common patterns are: type I, single uniform unit; type II, groove with two apexes; type III, fenestrations with muscular bridges; type IV, complete separation in two adjacent heads; and type $\mathrm{V}$, complete separation with two distant heads. An appropriate analysis of the papillary damage must include the division that can occur according to two directions corresponding to a sagittal plane or to a coronal plane. One leads to a separate posterior leaflet head while the second leads to a separate commissural head. Then, the pathophysiology of ischemic mitral valve prolapse is divided in: (I) pattern of necrosis of a separate commissural head involving rupture of the harborage of the commissural chord; (II) pattern of necrosis of a single head papillary muscle subdivided in multiple heads evolving in partial rupture; (III) pattern of necrosis of a fenestrated papillary muscle with detachment of its main insertion supporting an 'incomplete' rupture. The pattern also called "incomplete rupture" mimics papillary muscle elongation. In anterior MI, the most common pattern of IMP is represented by necrosis of single papillary muscle with complete and total rupture (V) (Figure 2).

\section{Distribution of coronary blood flow in the papillary muscles}

The reported prevalence of scarce vascularization of PMPM among persons with a IMP ranges about $91 \%$ in our series. This variation is related to differences of coronary vascular distribution in papillary muscle. Nonhomogeneous distribution of blood supply accounts for the rare involvement of the anterior PM and all the segment of ventricular wall. In fact, the perfusion is guaranteed by both the left anterior descending coronary artery and diagonal branch. In addition, biomechanics evidence of the tension exerted by the chordae on ALPM suggest for a relatively low dynamic stress-strain due to its superficial location with regard to the annulus. The difference in the PMPM injury is related to greater sensitivity to ischemia (reported $91 \%$ of the cases in our works) because it is perfused by either the right coronary or the circumflex artery; moreover, biomechanics of PMPM is strongly associated to its location deep in the left ventricle that provokes a higher shear force. Analysis of PM microcirculation evokes an independent blood supply assured by a segmental distribution and a well-identified arterial trunk, named Kugel's artery that perforates the PM from base to apex (21). This finding relative to microcirculation and anatomical characteristics 
A
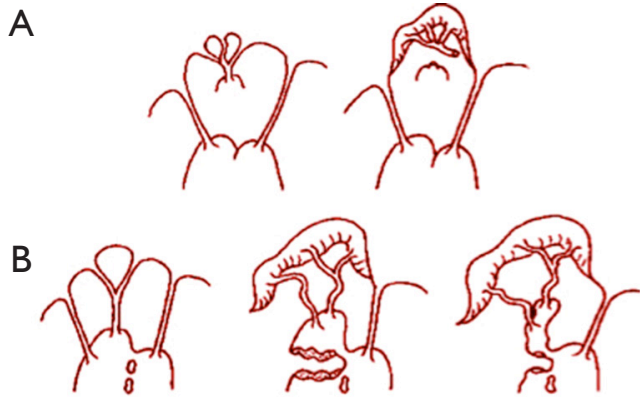

C

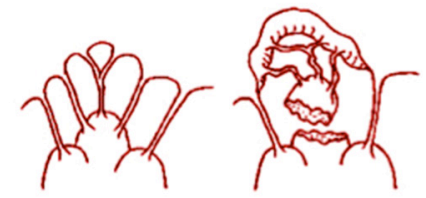

D

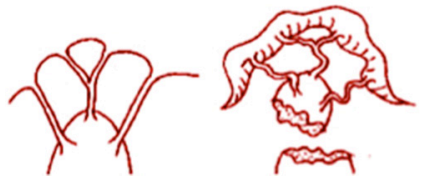

Figure 2 Mechanisms of ischemic valve prolapse (see text).

of PM allocate the relative importance of one of the two circulatory systems. Frailty of PM depends on the morphology and position of the PM within the ventricle and on the presence, muscular bridging, which favors collateralization. The evidence supporting the importance of the truncal system increases when the PM is more individualized from the ventricular wall, as in type IV-V. In this pattern the apex becomes more prone to rupture due to the fragility of its truncal blood supply and to the degree of physical stress. Limited injuries such as partial papillary muscle rupture or elongation limited to a single head are therefore more likely to happen than in other morphological patterns with multiple muscular bridges (pattern III) in which papillary muscles are protected by compensatory collateral vascularization. Normally the posterior PM is frequently divided into several heads and this more complex morphology than the anterior PM determines its usual site of ischemic injury. The lesion more frequently observed is partial PM rupture or elongation limited to a single head. Alternatively, an incomplete detachment of a head due to a rupture of its main insertion with the body occurs typically, remaining fixed to the ventricle via muscular bridges ('incomplete' papillary muscle rupture). The rate and topography of leaflet prolapsed is typically unequal for distribution. The disease is prior manifested by a prolapse of the posteromedial commissure, extended often in A2-A3 scallops $(2-4,22)$. In these cases, optimal surgical strategy is repair of mitral commissure and the neighboring involved scallops (23). IMR and prolapse are a consequence of adverse left ventricular remodelling after myocardial injury with enlargement of the left ventricular chamber and mitral annulus, leaflet tethering, and reduced closing forces.

Therefore, the complexity of injury has an effect on the imbalance between tethering forces and closing forces of the valvular and subvalvular apparatus (2,22,24-29). Our series confirms others observational studies that suggest for presence of primary lesion or dysfunction of PM leading to prolapse in $86,4 \%$ of IMR patients (30-33). We showed an involvement of antero-lateral PM (ALPM) in 18, $2 \%$ and postero-medial PM (PMPM) in 63, 8\% respectively (33). In $13.6 \%$, the prolapse was determined by the necrosis of a restricted area of the myocardium adjacent to the PM, which was responsible for its abnormal traction and of its dyssynchrony $(4,33)$.

\section{Evidence from randomized studies and observational reports}

Recently, we have confirmed the experience of the Cardiothoracic Surgical Trials Network (CTSN), which remarked the advantage of mitral-valve surgery associated to myocardial revascularization (CABG) in IMR. In their study, there was no difference in mortality and in the extent of adverse LV remodeling between the valve repair and replacement group. The rate of recurrence of moderate or severe mitral regurgitation over 2 years for mitral repair was higher for valve replacement $(58.8 \%$ vs. $3.8 \%, \mathrm{P}<0.001)$. Although, no significant between-group differences in rates of serious adverse events and overall readmissions were detected, valve repair patients experienced more serious adverse events related to heart failure $(\mathrm{P}=0.05)$ and cardiovascular readmissions $(\mathrm{P}=0.01)$, while in the replacement group patients had greater improvement in quality of life and functional status, as shown by the Minnesota Living with Heart Failure questionnaire $(\mathrm{P}=0.07)$ (34).

Although the clinical presentation of patients with IMP can vary from severe to moderate valve regurgitation evidence from observational series strongly suggests that surgical intervention is beneficial (1,34-37). In our group, we evaluated the effect of early surgery on long-term outcomes in 75 patients with mitral regurgitation for IMP. Rate of cardiacrelated death was $34.7 \%$ with a 5- and 10-year survival from cardiac-related events of $75.0 \%$ and $50.0 \%$, respectively. Patients with total rupture of papillary muscle and cardiogenic shock showed a higher rate of death in comparison to patients 
in which the culprit morphological injury was chordae lesion or incomplete rupture $(3,4,38)$. The clinical manifestations were related to the residual function of the mitral valve (severe or moderate incompetence), extension of MI, residual myocardial ischemia, and acquired complications such as left ventricular dysfunction and rhythm disturbance $(1,38,39)$. We identified independent predictors of poor outcomes including a preoperative LVEDD $>62 \mathrm{~mm}$, LVESD $>52 \mathrm{~mm}$, a previous anteroseptal MI, diffuse coronary artery disease, papillary anatomy type 1 , partial rupture of the papillary muscle, A1-A2 scallop prolapse and adverse postoperative mitral valve configuration (tenting area, tenting height, alfa-1 angle and alfa-2 angle). CTSN have showed that restrictive annuloplasty in moderate IMR does not provide better clinical outcomes when associated to myocardial revascularization (CABG) and these findings were confirmed by a systematic review of the current clinical evidences (40-44). The findings described by Michler $e t$ al. at 2-year outcomes of surgical treatment of moderate IMR revealed no difference among a combined approach including restrictive annuloplasty and coronary artery bypass grafting (CABG) vs. CABG-alone. Authors report no significant between-groups difference in LVESVI (41.2 $\pm 20.0 \mathrm{~mL}$ in the CABG-alone group vs. $43.2 \pm 20.6 \mathrm{~mL}$ in the combined undersizing annuloplasty and CABG group, respectively). The same result was evident in terms of left ventricular ejection fraction $(46.1 \% \pm 10.5 \%$ in the CABG-alone group vs. $45.6 \% \pm 10.0 \%$ in the associated surgery procedure group) (45). However, MR recurrence was 3 times higher in the CABG-alone group at 2 years and patients developing MR experienced a significant worsening LVESVI and reverse remodeling. The effective surgical advantage of valve repair in the context of IMR or IMP is still discussed (40-43). Undoubtedly, the evidence that a mitral leaflet prolapse in IMR should represent an indication to surgery of the mitral valve in combination with CABG has been reported (41). The early studies on noncorrected mitral regurgitation in the context of overlooked IMP date back in the era of cardiac catheterization (43-45). Similarly, several reports described the late outcomes of patients with coronary disease and moderate mitral valve dysfunction with leaflet prolapse not undergone to mitral repair $(45,46)$. Some patients with moderate IMR alone experienced an initial positive left ventricular remodeling with reduced shear stress and filling pressures and further normalization of valve incontinence (35). Conversely, some other studies report a further progressive decrease marked reduction of left ventricular dilation if the mitral valve is not addressed (47-52). Unfortunately, several factors as the era of the study, the cohort selected, and the method used to diagnose IMP (clinical exam vs. cardiac catheterization $v s$. echocardiography) are responsible of the wide degree of variation in the estimates of the prevalence of complications and outcomes. In this context, two large recent series have helped to better define the clinical course of unoperated IMP in the modern era $(40,41,53,54)$.

\section{Patient care}

Accurate diagnosis of IMP requires an assessment of symptoms after MI. The medical history should focus on determining the underlying clinical disorder that has led to IMR. Electrocardiography is a fundamental investigation to evaluate localization and extension of the necrosis secondly to evaluate cardiac rhythm. Transthoracic echocardiography can evaluate myocardial and valvular function and can help identify the mechanism and severity of IMP. The instrumental investigation is the first approach to assess critically patients and often provides a semiquantitative scale of grade mitral regurgitation 3+ (moderate), and 4+ (severe). Patients less severe has grade $1+$ (trace) or grade 2+ (mild) $(55,56)$.

Patients with a total rupture of ALPM who have severe mitral regurgitation with cardiogenic shock symptoms, pulmonary edema, severe left ventricular dysfunction (ejection fraction, $<40 \%$ ), dilatation (left ventricular end-systolic dimension, $>40 \mathrm{~mm}$ ), or both should require urgent surgical treatment of the mitral valve (chordalsparring mitral valve replacement or mitral valve repair) $(51,52,56)$. This category of patients benefits of newer echocardiographic techniques such as tissue Doppler imaging of the mitral-valve annulus that may be used to determine left ventricular end-diastolic pressure and to assess diastolic dysfunction (56). Likewise, in symptomatic patients with moderate left ventricular dysfunction or dilatation, with or without atrial fibrillation or pulmonary hypertension surgical treatment can be delayed after 60 days $(3,4)$. Patients with common inferior MI usually manifest chordae lesion injury, mild-to-moderate mitral regurgitation and no evidence of left ventricular dysfunction or dilatation and should be monitored in case of exacerbation of symptoms or increased mitral regurgitation. Frequently, these patients had a PCI-stenting procedure $(3,4)$. Before the advent of mitralvalve repair, valve replacement was the preferred procedure for severe IMR alone or with leaflet prolapse (23). Mitral valve sparring replacement is very effective to provide lasting 

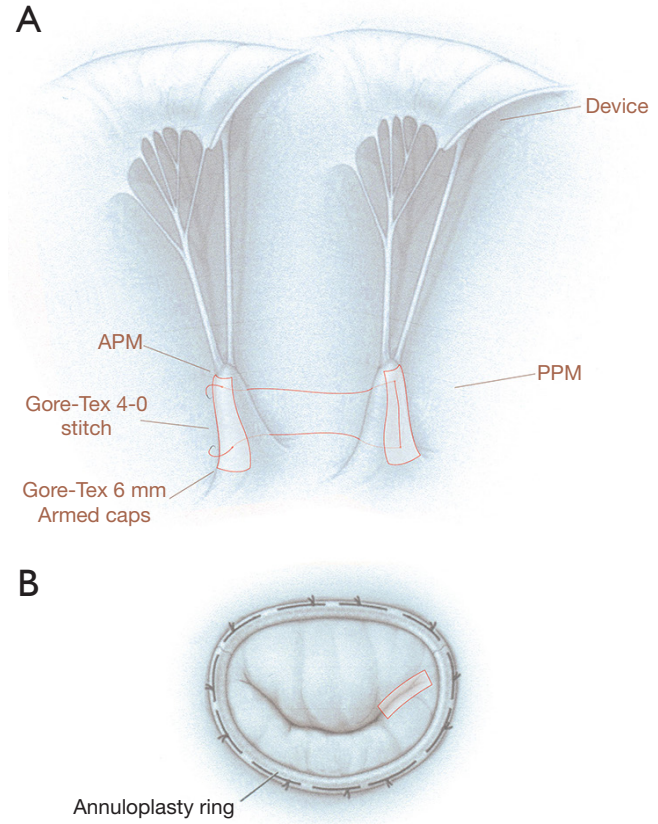

Figure 3 Surgical reparative strategies. (A) Papillary muscle approximation (PMA). A Gore-tex cap is used to reinforce the heads of the papillary muscle and a Gore-tex 4-0 suture is used to approximate the two papillary muscles and therefore increase leaflets coaptation; (B) mitral annuloplasty performed in association to PMA (red rectangle). APM, anterior papillary musclePPM: posterior papillary muscle.

relief in patients with advanced age, total papillary muscle rupture, severe left ventricular dysfunction and when complex surgical procedure is required (39-41,49,53,54,57-59). In addition, in the case of extensive prolapse of A2-A3 scallops mitral valve sparring operations should be the preferred option (18,34-36,53,54,57-59). Recently, chordalsparing valve replacement for MR has taken the scenario of ischemic mitral valve surgery as a suitable alternative to repair of the leaflet prolapse. Priority factor to be taken into account in determining success of a repair procedure is individual and institutional experience. Many centers worldwide have the lowest mortality rates and the highest proportion of patients undergoing mitral-valve repair rather than replacement (60). Appropriate parameters or variables selection predicting prognosis or outcome of mitral repair are critical to guarantee good result. Observational studies evaluated a set of clinical and echocardiographic variables able to predict recurrence of MR after surgical repair $(1,2,27,61,62)$. The evaluation of risk-benefit in successful repair depends on surgeons' experience when counseling the patient and may suggest a second option. After IMP surgery, a functional type II residual MR with structurally normal mitral valve might occur. Even more, the failure of the repair demands to perform mitral replacement and the decision between a mechanical valve and a bioprosthesis should be discussed with the patient before the operation. The presence of systolic restricted leaflet motion on the remaining leaflets (type III-b) and some degree of annular dilatation (functional type I) might also be present emphasizing the initial geometric disorder often difficult to solve $(23,63)$.

In our series, 214 patients have been treated for IMR and out of these 75 had IMP. Mitral valve repair was possible in $90.7 \%$ of cases and valve replacement was required in $9.3 \%$ of the cases $(3,4)$. Leaflet prolapse with otherwise structurally normal mitral valve (functional type II) was observed in all patients intraoperatively. In $88.0 \%$ of cases the mechanism of prolapse related PM injury and in $12.0 \%$ to chordal. Anatomical classification of PM injury demonstrated an antero-lateral PM lesion in $20.0 \%$ of the patients, postero-medial PM lesion in $66.7 \%$ of the cases and postero-medial PM elongation in $13.3 \%$ of the cases. Mitral replacement was performed for patients with isolated total PM rupture or a partial rupture with an extensive prolapse of A3-PC-P3 scallops. The prolapse of the posteromedial commissure, the more frequently encountered lesion, was repaired with isolated stich. For the anterior leaflet, a number of different techniques may be used to repair including artificial chordal replacement with Gore-Tex (expanded polytetrafluoroethylene sutures), chordal transposition and limited triangular resection. The prolapse of the posterior middle scallop (P2), only encountered in a small percentage of patients with IMR, is usually repaired with limited resection of this scallop. Finally, in all cases a downsized annuloplasty was performed to stabilize the annulus, which was normally found to be distorted or dilated or both (64-69).

Also, another important point thoroughly discussed in the literature is represented by the real benefits of the treatment of papillary muscles in reducing left ventricular dysfunction in IMR surgery. Papillary muscle approximation seems to be the more effective alternative among the available options and various approach proposed (70) (Figure 3). However, there are no randomized trials in which the real benefit of those procedures in the long-term follow-up is demonstrated (71-76).

In our series, concomitant CABG was performed in all patients using an internal thoracic artery to bypass left 
anterior descending artery lesions. We routinely advise intraoperative transesophageal echocardiography during IMR surgery to evaluate the effectiveness of the repair. Transesophageal echocardiography provides precise anatomic and functional information which are critical for the understanding the mechanism and severity of mitral regurgitation. The extent of leaflet prolapse, the condition of the subvalvular apparatus, the diameter of the mitral annulus, and ventricular function are indeed fundamental variables to plan the best operative strategy (55). Follow-up after mitral-valve repair with transthoracic echocardiography is recommended 6 to 8 weeks after discharge. Usually patients are then referred back to the care of their cardiologist and general practitioner, and we advise the echocardiography to be performed annually thereafter.

\section{Complications and pitfalls}

Operative mortality associated to mitral-valve repair or replacement in IMR alone or with leaflet prolapse is $6 \%$ or less. In our experience, multisystem organ failure (37.5\%), heart failure $(12.5 \%)$, and renal failure $(10.0 \%)$ represented the most frequent primary causes of death. Predictors of mortality included advanced age and poorer New York Heart Association class which are frequently encountered in patients who suffered PM rupture and cardiogenic shock associated to extended anterior MI $(53,57,58)$. Other determinants are represented by lower preoperative ejection fraction, high preoperative left ventricular endsystolic dimension, and other coexisting conditions including diabetes, renal disease, chronic lung disease, and obesity. The Society of Thoracic Surgeons National Adult Cardiac Surgery Database, identified in prolonged ( $>24 \mathrm{~h}$ ) ventilatory support (10.4\% of patients), renal failure (4.8\%), and stroke $(2.4 \%)$ the most significant postoperative complications at discharge Thromboembolism after mitralvalve repair occurs in approximately $2.8 \%$ of the patients within the first 12 months after surgery. Intraoperative conversion to mitral-valve replacement ranges between $2 \%$ to $10 \%$ of cases $(36,39,56,77)$. However, the most relevant complication of mitral-valve repair is represented by the recurrence of $M R$, with a reported incidence spanning between $5-53 \%$ of patients among the studies often requiring reoperation $(3,45,58,77-79)$.

In our series on IMP, the rate of late cardiac events (medical and surgical complications) were approximately $34.7 \%$ with a mean survival of 114.2 months including patients with in-hospital mortality. Survival from cardiac- related events at 5 and 10 years was $75.0 \%$ and $50.0 \%$, respectively. Presence of at least one among age $>70$ years, total rupture of ALPM in anterior IMA, severe mitral incompetence, cardiogenic shock and surgery before 30 days was associated to increased rate of cardiac-related events. Freedom from recurrent MR in patients with IMP was $76.5 \%$ at 10 years, while $24 \%$ of the patients required reoperation. Of note the majority of the patients developed some sort of rhythm disturbances before the operation, namely atrioventricular blocks and QRS prolongation, suggesting the idea that appearance of these abnormalities should prompt decision on some form of intervention. However, further investigations are necessary to confirm this finding.

\section{Conclusions}

IMP is a daunting condition in IMR requiring a careful consideration in terms of both diagnosis and treatment. Currently available literature is unable to produce a final statement on the best therapeutic strategy to adopt in IMR; however, the presence of IMP is regarded as an indication to perform surgery. Indeed, it underlies more than a simple annular dilation, which can be normally addressed by myocardial revascularization interrupting the ventricular remodeling process, Conversely, IMP indicates an alteration of more than one of the components of the mitral apparatus and valve configuration (annulus, PM, chordae, LV geometry) and therefore requires a more meticulous attitude during the operative work-up. In this scenario, papillary muscle surgery is still a debated argument and there is no final answer on the correct surgical approach to be adopted. A randomized trial to elucidate this point would be desirable in this context.

\section{Acknowledgements}

None.

\section{Footnote}

Conflicts of Interest: The authors have no conflicts of interest to declare.

\section{References}

1. Nishimura RA, Otto CM, Bonow RO, et al. 2014 AHA/ ACC guideline for the management of patients with 
valvular heart disease: executive summary: a report of the American College of Cardiology/American Heart Association Task Force on Practice Guidelines. J Am Coll Cardiol 2014;63:2438-88.

2. Lancellotti P, Moura L, Pierard LA, et al. European Association of Echocardiography recommendations for the assessment of valvular regurgitation. Part 2: mitral and tricuspid regurgitation (native valve disease). Eur J Echocardiogr 2010;11:307-32.

3. Nappi F, Nenna A, Spadaccio C, et al. Predictive factors of long-term results following valve repair in ischemic mitral valve prolapse. Int J Cardiol 2016;204:218-28.

4. Jouan J, Tapia M, C Cook R, et al. Ischemic mitral valve prolapse: mechanisms and implications for valve repair. Eur J Cardiothorac Surg 2004;26:1112-7.

5. Marwick TH, Lancellotti P, Pierard L. Ischaemic mitral regurgitation: mechanisms and diagnosis. Heart 2009;95:1711-8.

6. Otsuji Y, Levine RA, Takeuchi M, et al. Mechanism of ischemic mitral regurgitation. J Cardiol 2008;51:145-56.

7. Kalra K, Wang Q, McIver BV, et al. Temporal changes in interpapillary muscle dynamics as an active indicator of mitral valve and left ventricular interaction in ischemic mitral regurgitation. J Am Coll Cardiol 2014;64:1867-79.

8. Sanz J, Weinsaft JW. Ischemic mitral regurgitation: is mitral valve physiology moving from global to local? J Am Coll Cardiol 2014;64:1880-2.

9. Agricola E, Oppizzi M, Pisani M, et al. Ischemic mitral regurgitation: mechanisms and echocardiographic classification. Eur J Echocardiogr 2008;9:207-21.

10. Lancellotti P, Marwick T, Pierard LA. How to manage ischaemic mitral regurgitation. Heart 2008;94:1497-502.

11. Langer F, Rodriguez F, Ortiz S, et al. Subvalvular repair: the key to repairing ischemic mitral regurgitation? Circulation 2005;112:I383-9.

12. Shudo Y, Matsumiya G, Sakaguchi T, et al. Assessment of changes in mitral valve configuration with multidetector computed tomography: impact of papillary muscle imbrication and ring annuloplasty. Circulation 2010;122:S29-36.

13. Yu HY, Su MY, Liao TY, et al. Functional mitral regurgitation in chronic ischemic coronary artery disease: analysis of geometric alterations of mitral apparatus with magnetic resonance imaging. J Thorac Cardiovasc Surg 2004;128:543-51.

14. Kaji S, Kim K, Furukawa Y. Why does papillary separation play a major role in functional mitral regurgitation caused by left ventricular function? J Thorac Cardiovasc Surg
2014;148:3252-4.

15. Kim K, Kaji S, An Y, et al. Interpapillary muscle distance independently affects severity of functional mitral regurgitation in patients with systolic left ventricular dysfunction. J Thorac Cardiovasc Surg 2014;148:434-40.e1.

16. Bolling SF, Deeb GM, Brunsting LA, et al. Early outcome of mitral valve reconstruction in patients with end-stage cardiomyopathy. J Thorac Cardiovasc Surg 1995;109:67682; discussion 682-3.

17. Bolling SF, Pagani FD, Deeb GM, et al. Intermediateterm outcome of mitral reconstruction in cardiomyopathy. J Thorac Cardiovasc Surg 1998;115:381-6; discussion 387-8.

18. Bax JJ, Braun J, Somer ST, et al. Restrictive annuloplasty and coronary revascularization in ischemic mitral regurgitation results in reverse left ventricular remodeling. Circulation 2004;110:II103-8.

19. Lamas GA, Mitchell GF, Flaker GC, et al. Clinical significance of mitral regurgitation after acute myocardial infarction. Survival and Ventricular Enlargement Investigators. Circulation 1997;96:827-33.

20. Grigioni F, Enriquez-Sarano M, et al. Ischemic mitral regurgitation: long-term outcome and prognostic implications with quantitative Doppler assessment. Circulation 2001;103:1759-64.

21. Estes EH Jr, Dalton FM, Entman ML, et al. The anatomy and blood supply of the papillary muscles of the left ventricle. Am Heart J 1966;71:356-62.

22. Ray S. The echocardiographic assessment of functional mitral regurgitation. Eur J Echocardiogr 2010;11:i11-17.

23. Carpentier A. Cardiac valve surgery--the "French correction". J Thorac Cardiovasc Surg 1983;86:323-37.

24. Hung J, Papakostas L, Tahta SA, et al. Mechanism of recurrent ischemic mitral regurgitation after annuloplasty: continued LV remodeling as a moving target. Circulation 2004;110:II85-90.

25. Zhu F, Otsuji Y, Yotsumoto G, et al. Mechanism of persistent ischemic mitral regurgitation after annuloplasty: importance of augmented posterior mitral leaflet tethering. Circulation 2005;112:I396-401.

26. Argulian E. Valvular disease, myocardial mechanics, and valve guidelines. JACC Cardiovasc Imaging 2015;8:382.

27. Magne J, Pibarot P, Dagenais F, et al. Preoperative posterior leaflet angle accurately predicts outcome after restrictive mitral valve annuloplasty for ischemic mitral regurgitation. Circulation 2007;115:782-91.

28. Evangelista A, Flachskampf F, Lancellotti P, et al. European Association of Echocardiography recommendations for standardization of performance, 
digital storage and reporting of echocardiographic studies. Eur J Echocardiogr 2008;9:438-48.

29. Yiu SF, Enriquez-Sarano M, Tribouilloy C, et al. Determinants of the degree of functional mitral regurgitation in patients with systolic left ventricular dysfunction: A quantitative clinical study. Circulation 2000;102:1400-6.

30. Gorman JH 3rd, Jackson BM, Gorman RC, et al. Papillary muscle discoordination rather than increased annular area facilitates mitral regurgitation after acute posterior myocardial infarction. Circulation 1997;96:II-124-7.

31. Nishimura RA, Schaff HV, Shub C, et al. Papillary muscle rupture complicating acute myocardial infarction: analysis of 17 patients. Am J Cardiol 1983;51:373-7.

32. Patel AM, Miller FA Jr, Khandheria BK, et al. Role of transesophageal echocardiography in the diagnosis of papillary muscle rupture secondary to myocardial infarction. Am Heart J 1989;118:1330-3.

33. Ishii K, Myojin K, Ishibashi Y, et al. Surgical management of papillary muscle rupture following acute myocardial infarction. Kyobu Geka 2005;58:295-9.

34. Goldstein D, Moskowitz AJ, Gelijns AC, et al. TwoYear Outcomes of Surgical Treatment of Severe Ischemic Mitral Regurgitation. N Engl J Med 2016;374:344-53.

35. Harris KM, Sundt TM 3rd, Aeppli D, et al. Can late survival of patients with moderate ischemic mitral regurgitation be impacted by intervention on the valve? Ann Thorac Surg 2002;74:1468-75.

36. Wong DR, Agnihotri AK, Hung JW, et al. Long-term survival after surgical revascularization for moderate ischemic mitral regurgitation. Ann Thorac Surg 2005;80:570-7.

37. Borger MA, Alam A, Murphy PM, et al. Chronic ischemic mitral regurgitation: repair, replace or rethink? Ann Thorac Surg 2006;81:1153-61.

38. Hashim SW, Youssef SJ, Ayyash B, et al. Pseudoprolapse of the anterior leaflet in chronic ischemic mitral regurgitation: identification and repair. J Thorac Cardiovasc Surg 2012;143:S33-7.

39. Wrobel K, Stevens SR, Jones RH, et al. Influence of Baseline Characteristics, Operative Conduct, and Postoperative Course on 30-Day Outcomes of Coronary Artery Bypass Grafting Among Patients With Left Ventricular Dysfunction: Results From the Surgical Treatment for Ischemic Heart Failure (STICH) Trial. Circulation 2015;132:720-30.

40. Sundt TM. Surgery for ischemic mitral regurgitation. N Engl J Med 2014;371:2228-9.
41. Smith PK, Puskas JD, Ascheim DD, et al. Surgical treatment of moderate ischemic mitral regurgitation. $\mathrm{N}$ Engl J Med 2014;371:2178-88.

42. Pierard LA. Surgical treatment of moderate ischemic mitral regurgitation. N Engl J Med 2015;372:1770.

43. Gillinov AM, Wierup PN, Blackstone EH, et al. Is repair preferable to replacement for ischemic mitral regurgitation? J Thorac Cardiovasc Surg 2001;122:1125-41.

44. Castleberry AW, Williams JB, Daneshmand MA, et al. Surgical revascularization is associated with maximal survival in patients with ischemic mitral regurgitation: a 20-year experience. Circulation 2014;129:2547-56.

45. Michler RE, Smith PK, Parides MK, et al. Two-Year Outcomes of Surgical Treatment of Moderate Ischemic Mitral Regurgitation. N Engl J Med 2016;374:1932-41.

46. Castleberry AW, Williams JB, Daneshmand MA, et al. Response to letter regarding article, "surgical revascularization is associated with maximal survival in patients with ischemic mitral regurgitation: a 20-year experience". Circulation 2015;131:e378-9.

47. Ellis SG, Whitlow PL, Raymond RE, et al. Impact of mitral regurgitation on long-term survival after percutaneous coronary intervention. Am J Cardiol 2002;89:315-8.

48. Trichon BH, Glower DD, Shaw LK, et al. Survival after coronary revascularization, with and without mitral valve surgery, in patients with ischemic mitral regurgitation. Circulation 2003;108 Suppl 1:II103-10.

49. Kang DH, Kim MJ, Kang SJ, et al. Mitral valve repair versus revascularization alone in the treatment of ischemic mitral regurgitation. Circulation 2006;114:I499-503.

50. Diodato MD, Moon MR, Pasque MK, et al. Repair of ischemic mitral regurgitation does not increase mortality or improve long-term survival in patients undergoing coronary artery revascularization: a propensity analysis. Ann Thorac Surg 2004;78:794-9; discussion 794-9.

51. Tolis GA Jr, Korkolis DP, Kopf GS, et al.

Revascularization alone (without mitral valve repair) suffices in patients with advanced ischemic cardiomyopathy and mild-to-moderate mitral regurgitation. Ann Thorac Surg 2002;74:1476-80; discussion 1480-1.

52. Maltais S, Schaff HV, Daly RC, et al. Mitral regurgitation surgery in patients with ischemic cardiomyopathy and ischemic mitral regurgitation: factors that influence survival. J Thorac Cardiovasc Surg 2011;142:995-1001.

53. Acker MA, Parides MK, Perrault LP, et al. Mitral-valve repair versus replacement for severe ischemic mitral regurgitation. N Engl J Med 2014;370:23-32. 
54. Nappi F, Spadaccio C. Coronary artery bypass grafting (CABG) alone in moderate ischemic mitral regurgitation: is CABG really enough? Ann Transl Med 2016;4:413.

55. Zoghbi WA, Enriquez-Sarano M, Foster E, et al. Recommendations for evaluation of the severity of native valvular regurgitation with two-dimensional and Doppler echocardiography. J Am Soc Echocardiogr 2003;16:777-802.

56. Bonow RO, Carabello BA, Chatterjee K, et al. 2008 focused update incorporated into the ACC/AHA 2006 guidelines for the management of patients with valvular heart disease: a report of the American College of Cardiology/American Heart Association Task Force on Practice Guidelines (Writing Committee to revise the 1998 guidelines for the management of patients with valvular heart disease). Endorsed by the Society of Cardiovascular Anesthesiologists, Society for Cardiovascular Angiography and Interventions, and Society of Thoracic Surgeons. J Am Coll Cardiol 2008;52:e1-142.

57. Magne J, Pierard LA. Surgery for severe ischemic mitral regurgitation. N Engl J Med 2014;370:1462.

58. Nappi F, Lusini M, Spadaccio C, et al. Papillary Muscle Approximation Versus Restrictive Annuloplasty Alone for Severe Ischemic Mitral Regurgitation. J Am Coll Cardiol. 2016;67:2334-46.

59. Nappi F, Spadaccio C, Fraldi M. Reply: Papillary Muscle Approximation Is an Anatomically Correct Repair for Ischemic Mitral Regurgitation. J Am Coll Cardiol 2016;68:1147-8

60. Gammie JS, O'Brien SM, Griffith BP, et al. Influence of hospital procedural volume on care process and mortality for patients undergoing elective surgery for mitral regurgitation. Circulation 2007;115:881-7.

61. Kron IL, Hung J, Overbey JR, et al. Predicting recurrent mitral regurgitation after mitral valve repair for severe ischemic mitral regurgitation. J Thorac Cardiovasc Surg 2015;149:752-61.e1.

62. Messas E, Bel A, Szymanski C, et al. Relief of mitral leaflet tethering following chronic myocardial infarction by chordal cutting diminishes left ventricular remodeling. Circ Cardiovasc Imaging 2010;3:679-86.

63. Llaneras MR, Nance ML, Streicher JT, et al. Pathogenesis of ischemic mitral insufficiency. J Thorac Cardiovasc Surg 1993;105:439-42; discussion 442-3.

64. Isnard R, Acar C. The mitral annulus area: a useful tool for the surgeon. J Heart Valve Dis 2008;17:243-50.

65. Nappi F, Spadaccio C, Chello M, et al. Double row of overlapping sutures for downsizing annuloplasty decreases the risk of residual regurgitation in ischaemic mitral valve repair. Eur J Cardiothorac Surg 2016;49:1182-7.

66. Nappi F, Spadaccio C, Al-Attar N, et al. Downsizing annuloplasty in ischemic mitral regurgitation: double row overlapping suture to avoid ring disinsertion in valve repair. Surg Technol Int 2014;25:203-6.

67. Siefert AW, Pierce EL, Lee M, et al. Suture forces in undersized mitral annuloplasty: novel device and measurements. Ann Thorac Surg 2014;98:305-9.

68. Jassar AS, Vergnat M, Jackson BM, et al. Regional annular geometry in patients with mitral regurgitation: implications for annuloplasty ring selection. Ann Thorac Surg 2014;97:64-70.

69. De Simone R, Wolf I, Mottl-Link S, et al. A clinical study of annular geometry and dynamics in patients with ischemic mitral regurgitation: new insights into asymmetrical ring annuloplasty. Eur J Cardiothorac Surg 2006;29:355-61.

70. Rama A, Nappi F, Praschker BG, et al. Papillary muscle approximation for ischemic mitral valve regurgitation. J Card Surg 2008;23:733-5.

71. Kron IL, Green GR, Cope JT. Surgical relocation of the posterior papillary muscle in chronic ischemic mitral regurgitation. Ann Thorac Surg 2002;74:600-1.

72. Hvass U, Tapia M, Baron F, et al. Papillary muscle sling: a new functional approach to mitral repair in patients with ischemic left ventricular dysfunction and functional mitral regurgitation. Ann Thorac Surg 2003;75:809-11.

73. Roshanali F, Vedadian A, Shoar S, et al. Efficacy of papillary muscle approximation in preventing functional mitral regurgitation recurrence in high-risk patients with ischaemic cardiomyopathy and mitral regurgitation. Acta Cardiol 2013;68:271-8.

74. Fattouch K, Castrovinci S, Murana G, et al. Papillary muscle relocation and mitral annuloplasty in ischemic mitral valve regurgitation: midterm results. J Thorac Cardiovasc Surg 2014;148:1947-50.

75. Mandegar MH, Saidi B, Yousefnia MA, et al. Longterm effect of papillary muscle approximation combined with ventriculoplasty on left ventricle function in patients with ischemic cardiomyopathy and functional mitral regurgitation. Eur J Cardiothorac Surg 2011;40:756-60.

76. Yousefnia MA, Dehestani A, Saidi B, et al. Papillary muscle repositioning in valve replacement for left ventricular dysfunction: ischemic mitral regurgitation. Ann Thorac Surg 2010;90:497-502.

77. Kron IL, Perrault LP, Acker MA. We need a better way to repair ischemic mitral regurgitation. J Thorac Cardiovasc 
Surg 2015;150:428.

78. Kuwahara E, Otsuji Y, Iguro Y, et al. Mechanism of recurrent/persistent ischemic/functional mitral regurgitation in the chronic phase after surgical annuloplasty: importance of augmented posterior leaflet

Cite this article as: Nappi F, Cristiano S, Nenna A, Chello M. Ischemic mitral valve prolapse. J Thorac Dis 2016;8(12):37523761. doi: $10.21037 /$ jtd.2016.12.33 tethering. Circulation 2006;114:I529-34.

79. Mihaljevic T, Lam BK, Rajeswaran J, et al. Impact of mitral valve annuloplasty combined with revascularization in patients with functional ischemic mitral regurgitation. J Am Coll Cardiol 2007;49:2191-201. 